\title{
Effect of nanocrystalline surface of substrate on microstructure and wetting of PEO coatings
}

\author{
H R MASIHA, H R BAGHERI, M GHEYTANI, M ALIOFKHAZRAEI*, \\ A SABOUR ROUHAGHDAM and T SHAHRABI \\ Department of Materials Science, Faculty of Engineering, Tarbiat Modares University, Tehran, P.O. Box: 14115-143, Iran
}

MS received 12 September 2013; accepted 15 February 2015

\begin{abstract}
In this research, effect of surface mechanical attrition treatment (SMAT) was studied on characteristics of the coatings formed using plasma electrolyte oxidation (PEO) on AA1230 aluminium. To do so, first, the samples were coated with and without SMAT pre-process. Coating by PEO method was carried out in two phosphate-based and silicate-based suspensions of silicon nitride nanoparticles for $10 \mathrm{~min}$. Next, to study the distribution of the nanoparticles and elements inside the coating, surface morphology of the samples was examined using scanning electron microscopy and energy dispersive spectroscopy. In addition, wettability test was performed on all samples using the deionized water. Also, droplet expansion manner on the porous oxide coating surface and its relation with fine structure of the coating was investigated. The results indicated that samples coated in silicate-based electrolyte have a relatively rougher microstructure as compared to samples coated in phosphate-based electrolyte. The average surface pores area percentage of the samples coated in silicate-based electrolytes was $13.9 \%$ greater than that of samples coated in phosphate-based electrolyte. Moreover, the average height to diameter $(h / d)$ value obtained from wettability test for samples coated in silicate-based electrolyte was $13.3 \%$ greater than that of phosphate-based electrolyte.
\end{abstract}

Keywords. Aluminium; nanocrystallization; nanoparticles; plasma electrolyte oxidation; surface mechanical attrition treatment.

\section{Introduction}

Severe plastic deformation can form nanocrystalline surface layers or bulk nanocrystalline metals and alloys more effectively. Nanocrystalline materials have grain, main grain, twins and displacements with average size of below $100 \mathrm{~nm} \cdot{ }^{1-3}$ Under higher dynamic strain rates, the grains become finer until creation of superfine and nanostructured grains. Within the last two decades several severe plastic deformation techniques have been developed for creation of nanostructured materials. Among the most important techniques, one can name equal-channel angular pressing (ECAP), ${ }^{4}$ high pressure torsion (HPT),${ }^{5}$ accumulative roll bonding $(\mathrm{ARB})^{6}$ and surface mechanical attrition treatment (SMAT). ${ }^{7}$

The basic principles of SMAT process is insertion of severe plastic deformation on surface layers of bulk metals at high strains and strain rates. Through SMAT process, hard balls with particular dimensions and materials hit in particular directions to the sample's surface and create plastic deformation on the surface. Each impact of one ball (with approximate speed of 1-20 $\mathrm{m} \mathrm{s}^{-1}$ ) creates a high strain plastic deformation at surface layer. ${ }^{8}$ Normally, further repetition of the impacts in different directions leads to successive deformation

\footnotetext{
*Author for correspondence (maliofkh@gmail.com,
} khazraei@modares.ac.ir) at surface layers. This miniaturization process continues until formation of nanometric crystallites. The nanostructured surface layers can have a thickness up to $50 \mu \mathrm{m}$ where their thickness depends on nature of the material, ball size and vibration frequency.

On the other hand, PEO coating technique has been recently among the novel coating methods for metals and have found various applications because of its simplicity, low costs, high cohesion strength of the coating with matrix metal, etc. PEO process can be performed in a suitable electrolyte through applying AC or DC voltage, which can result in the generation of small sparks along the coating surface. ${ }^{9}$ Sparks lifetime depends on PEO conditions and has been reported in the range of $50 \mu \mathrm{s}$ up to $3.5 \mathrm{~ms} .{ }^{10}$ Coating growth proceeds by further progress of sparking, which is probably a combination of anodic, thermal and plasma oxidation.

The main objective of this study is to compare the coatings formed at the surface of coarse-grains and fine-grains alloys; i.e., examining the effect of fine grain state of aluminium alloy on PEO process. The nanocrystallization of substrate (in this case used SMAT process) can probably improve the reaction-ability of samples and hence causes a significant improvement in the properties of coated samples. As, unlike the common plating techniques, PEO process is among the coating conversion methods and through which surface of metallic substrate react with electrolyte, effect of 
the surface structure is of high importance in this process. Therefore, elemental distribution, coating porosity and thickness, and nanoparticles distribution inside the coating were investigated in this article.

Table 1. Quantometric analysis of the aluminium sheet used in this work (wt\%).

\begin{tabular}{lcccccccc}
\hline $\mathrm{Al}$ & $\mathrm{Fe}+\mathrm{Si}$ & $\mathrm{Zn}$ & $\mathrm{Cu}$ & $\mathrm{Mg}$ & $\mathrm{Mn}$ & $\mathrm{V}$ & $\mathrm{Ti}$ & other \\
\hline Min 99.3 & 0.7 & 0.1 & 0.1 & 0.05 & 0.05 & 0.05 & 0.03 & 0.03 \\
\hline
\end{tabular}

\section{Experimental}

In this study, AA1230 aluminium alloy samples with dimensions of $0.1 \times 3 \times 2.5 \mathrm{~cm}^{3}\left(R_{\mathrm{a}}\right.$ (average value) $\left.<1 \mu \mathrm{m}\right)$ were used. Table 1 indicates chemical analysis of this aluminium. As schematically shown in figure 1, samples were put in SMAT device and processed at different directions. Through SMAT process, steel balls with diameter of $3.9 \mathrm{~mm}$ were used. Here, four samples were processed for $3 \mathrm{~h}$, whereas four other samples were processed for $9 \mathrm{~h}$ using the SMAT device. Then, the accurate weight of samples was measured using a high precision $(50 \mu \mathrm{g})$ digital micro-balance (AND
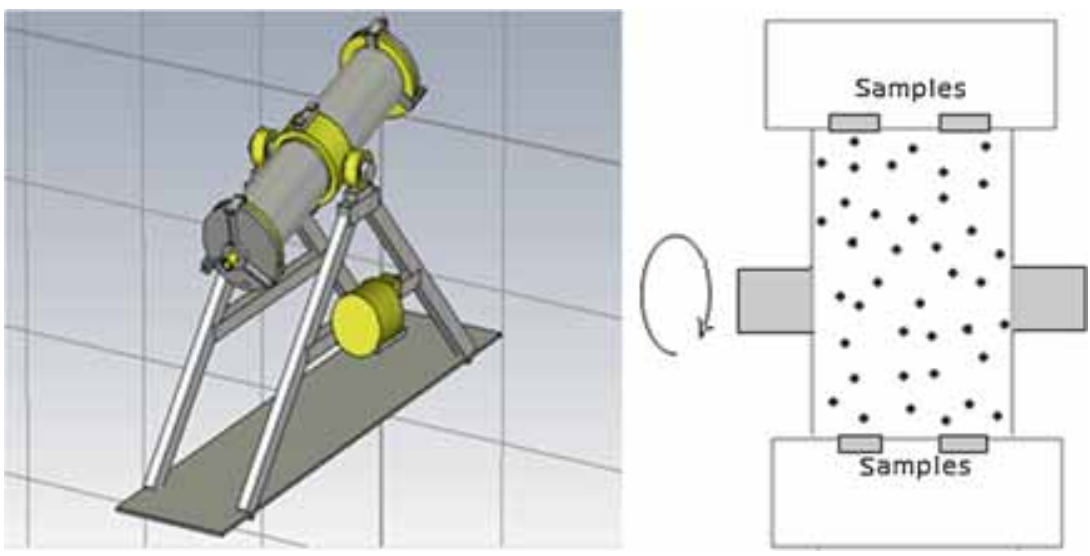

Figure 1. Schematic illustration and cross-section of SMAT device.

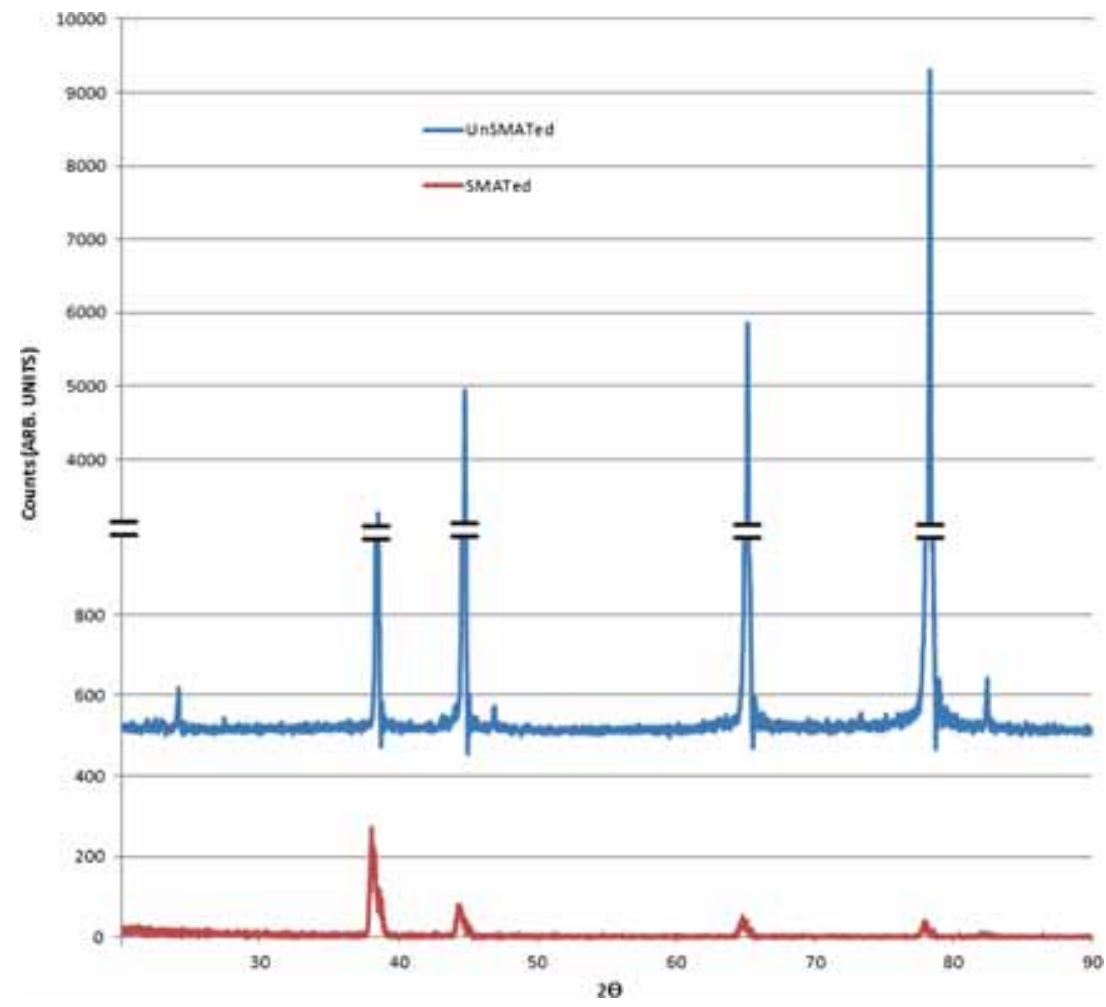

Figure 2. XRD pattern of aluminium surface with and without SMAT. 
Table 2. Composition of the electrolytes used in PEO coating process.

\begin{tabular}{lc}
\hline $\begin{array}{l}\text { Silicate-based electrolyte } \\
\left(\mathrm{g} \mathrm{l}^{-1}\right)\end{array}$ & $\begin{array}{c}\text { Phosphate-based electrolyte } \\
\left(\mathrm{g} \mathrm{l}^{-1}\right)\end{array}$ \\
\hline $\begin{array}{l}\text { Sodium silicate, } 6 \\
\text { Sodium aluminate, } 2\end{array}$ & $\begin{array}{c}\text { Sodium phosphate, } 6 \\
\text { Sodium aluminate, } 4 \\
\text { Sodium hydroxide, } 0.2 \\
\text { Silicon nitride } \\
\text { nanoparticles, } \quad 4\end{array}$ \\
\hline
\end{tabular}

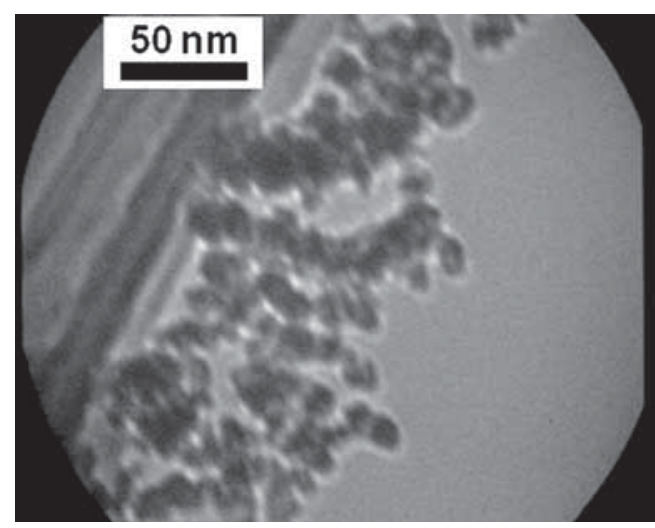

Figure 3. TEM image of silicon nitride $\left(\mathrm{Si}_{3} \mathrm{~N}_{4}\right)$ nanoparticles.

GR-202). Samples were tested by X-ray diffraction (XRD) analysis (Philips-X'pert, $\lambda_{\mathrm{Cu}}=1.54178 \AA$ ) to determine their average nanocrystallite size. XRD pattern of used aluminium with and without SMAT process is shown in figure 2. The observations showed that grain size of the samples decreases to $15 \mathrm{~nm}$.

The samples were coated by PEO process for 10 min under particular conditions, after their complete washing by alcohol. To perform coating process, two phosphate-based and silicatebased electrolytes (with compositions as shown in table 2) were used. Figure 3 illustrates transmission electron microscopy (TEM) image of silicon nitride $\left(\mathrm{Si}_{3} \mathrm{~N}_{4}\right)$ nanoparticles. The coating conditions of the samples are shown in table 3 .

To observe fine structure and elements and nanoparticles distribution, and comparing morphology of the coatings, scanning electron microscopy (SEM) (Zeiss, model: Sigma VP), energy dispersive spectroscopy (EDS) analysis with elemental map drawing were used. Figure 4 illustrates two EDS analysis of different samples as examples of obtained energy dispersive spectra. ImageJ software was used to determine the area percentage of the pores existing at the surface (figure 5). Furthermore, all samples were subjected to wettability test according to D7334 standard using deionized water and their wettability angle was measured. To carry out this test, Dinolite microscope (AM-413ZT), Hamilton syringe (with volume of $10 \mu \mathrm{l}$ ) and deionized water were used. Figure 6 presents a sample of droplet shape at various times after falling on the surface. For each photo taken at different time, droplet height $(h)$ and its diameter on the surface $(d)$ were measured and $h / d$ diagram was plotted $v s$. passing time. Figure 7 shows a measurement of $h$ and $d$ parameters.
Table 3. Coating conditions and codes of the samples.

\begin{tabular}{lccl}
\hline \multirow{2}{*}{$\begin{array}{l}\text { Code of } \\
\text { samples }\end{array}$} & $\begin{array}{c}\text { Time of } \\
\text { SMAT (h) }\end{array}$ & \multicolumn{2}{c}{ PEO coating } \\
\cline { 3 - 4 } SP-3-80 & 3 & 80 & Phosphate \\
SS-3-80 & 3 & 80 & Silicate \\
SP-3-160 & 3 & 160 & Phosphate \\
SS-3-160 & 3 & 160 & Silicate \\
SP-9-80 & 9 & 80 & Phosphate \\
SS-9-80 & 9 & 80 & Silicate \\
SP-9-160 & 9 & 160 & Phosphate \\
SS-9-160 & 9 & 160 & Silicate \\
UP-80 & UnSMATed & 80 & Phosphate \\
US-80 & UnSMATed & 80 & Silicate \\
UP-160 & UnSMATed & 160 & Phosphate \\
US-160 & UnSMATed & 160 & Silicate \\
\hline
\end{tabular}

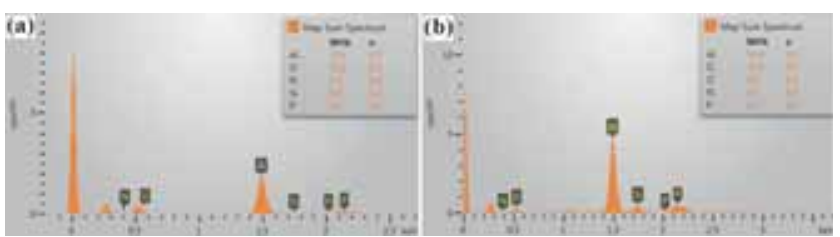

Figure 4. EDS spectra recorded from: (a) sample SP-3-80 and (b) sample US-80.

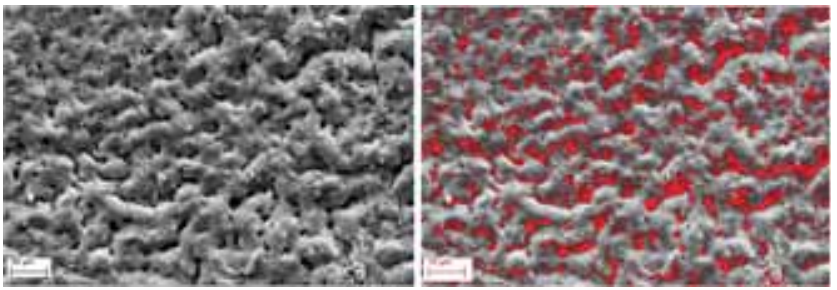

Figure 5. Determination of area percentage of the pores existing at the surface of sample SP-9-80.

\section{Results and discussion}

\subsection{Morphology and growth of coatings}

Figure 8 shows surface morphology of the samples imaged using SEM device. As shown in figure 8, samples coated in silicate-based electrolyte have a relatively rougher structure as compared to those coated in phosphate-based electrolyte. ${ }^{11-13}$ It seems that the roughness of samples coated in silicate-based electrolyte has dual-scale. ${ }^{14-16}$ Surface pores have different size and distribution depending on SMAT process and substrate activity. Apparently, SMATed samples do not show significant differences in terms of free surface structure of the unSMATed coating; however, different conditions of SMAT and different current densities of PEO process result in slight difference in porosity on free surface of the coating. Table 4 summarizes samples weight, thickness of the coatings and area percentage of the surface porosities. 


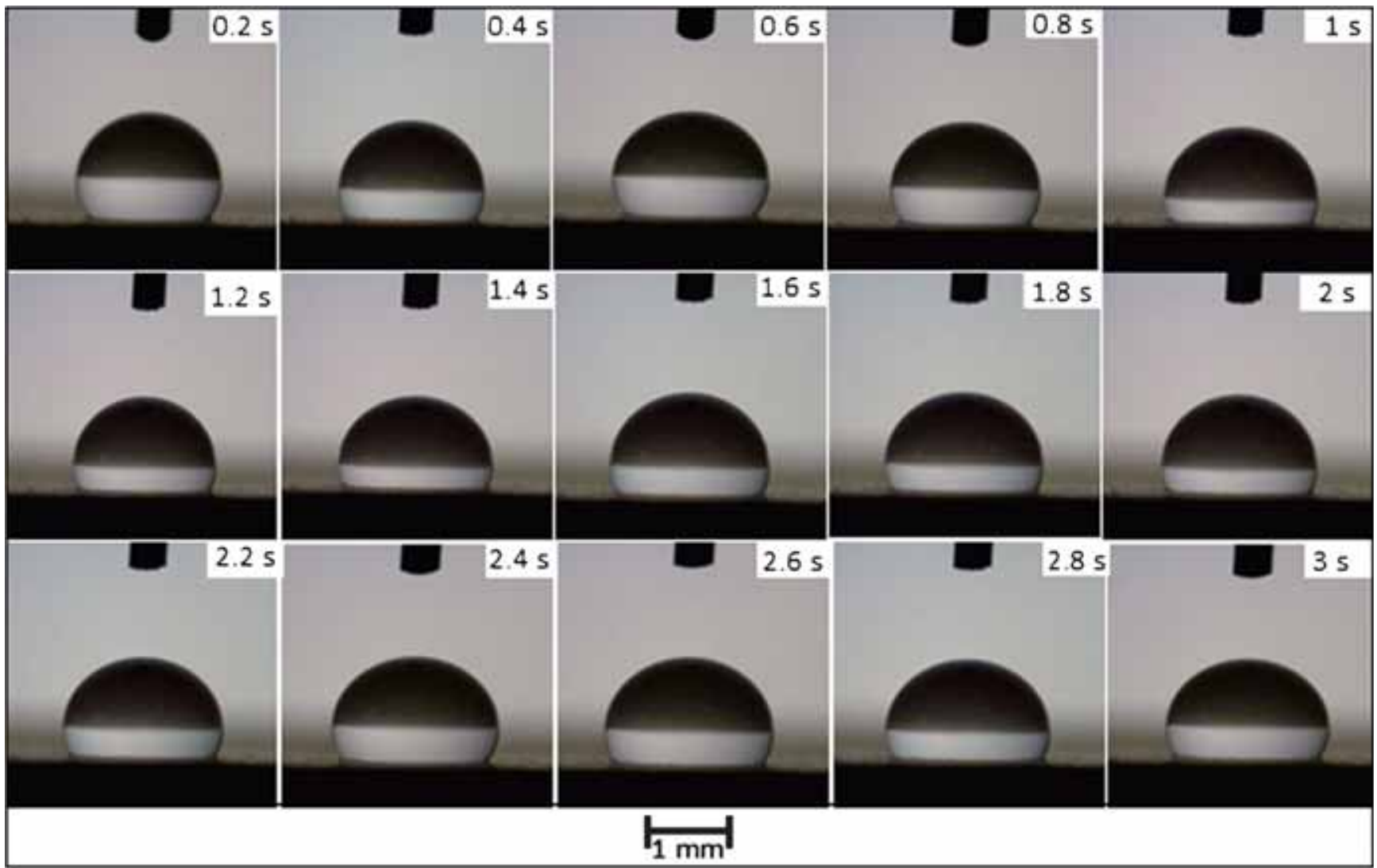

Figure 6. Sample of droplet expansion at various times after falling on surface (up to $3 \mathrm{~s}$ ).

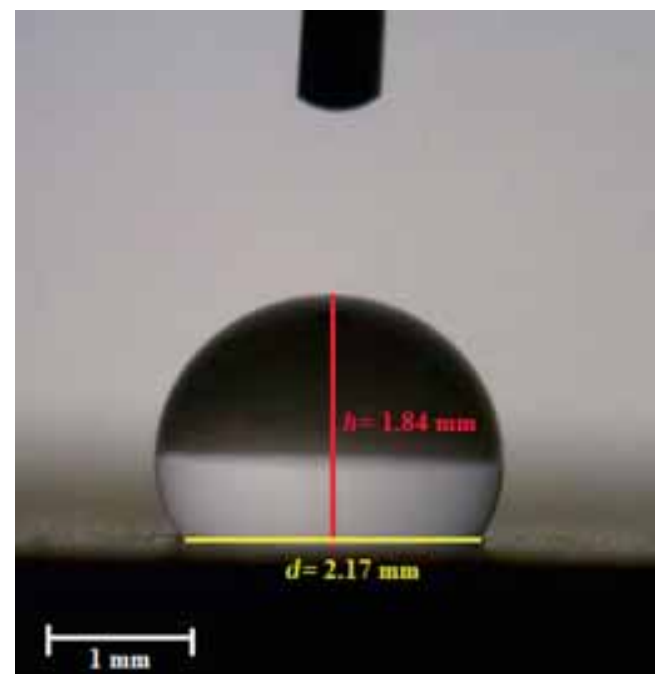

Figure 7. Sample of droplet expanded on the surface and measuring $h$ and $d$ on it.

For majority of the cases, area percentage of the porosities existing at the surface of sample coated in silicate-based electrolyte is greater than that of phosphate-based electrolyte. Moreover, in unSMATed samples, this value is higher than SMATed samples. The majority of the samples coated in silicate-based electrolyte indicate weight loss, implying further dissolution of the substrate as compared to outward coating growth during the PEO coating process. However, coatings created in phosphate-based electrolyte demonstrate different behaviour in terms of weight variations at various current densities, as for current densities of 80 and $160 \mathrm{~mA} \mathrm{~cm}^{-2}$ weight increase and loss was observed, respectively. Also, due to SMAT process, at current densities below $80 \mathrm{~mA} \mathrm{~cm}^{-2}$, weight increase was observed. Regarding the current densities above $160 \mathrm{~mA} \mathrm{~cm}^{-2}$, at shorter SMAT time (that is $3 \mathrm{~h}$ ) weight loss was observed, but in the case of longer SMAT time (that is $9 \mathrm{~h}$ ) weight increase was observed. This weight increase implies the faster growth of the coating, probably due to an increase in the number of active spots on the substrate. ${ }^{17-19}$

In the case of samples coated in silicate-based electrolyte, more elaborate examinations showed that 3-h SMAT process results in positive weight difference (i.e., weight increase) which is the greatest among the samples. This shows the severe effect of SMAT process on outward coating growth. As PEO coating has higher growth rate in silicate-based electrolyte, it can be stated that SMAT process is effective in growth acceleration. As the results show, the maximum obtained coating thickness is for sample SS-3-160. A comparison among the thickness of the obtained coatings reveals that SMAT process considerably enhances their thickness. As weight difference percentage of the coatings before and after SMAT process does not show a significant difference, it can be concluded that it was the effect of SMAT process that 

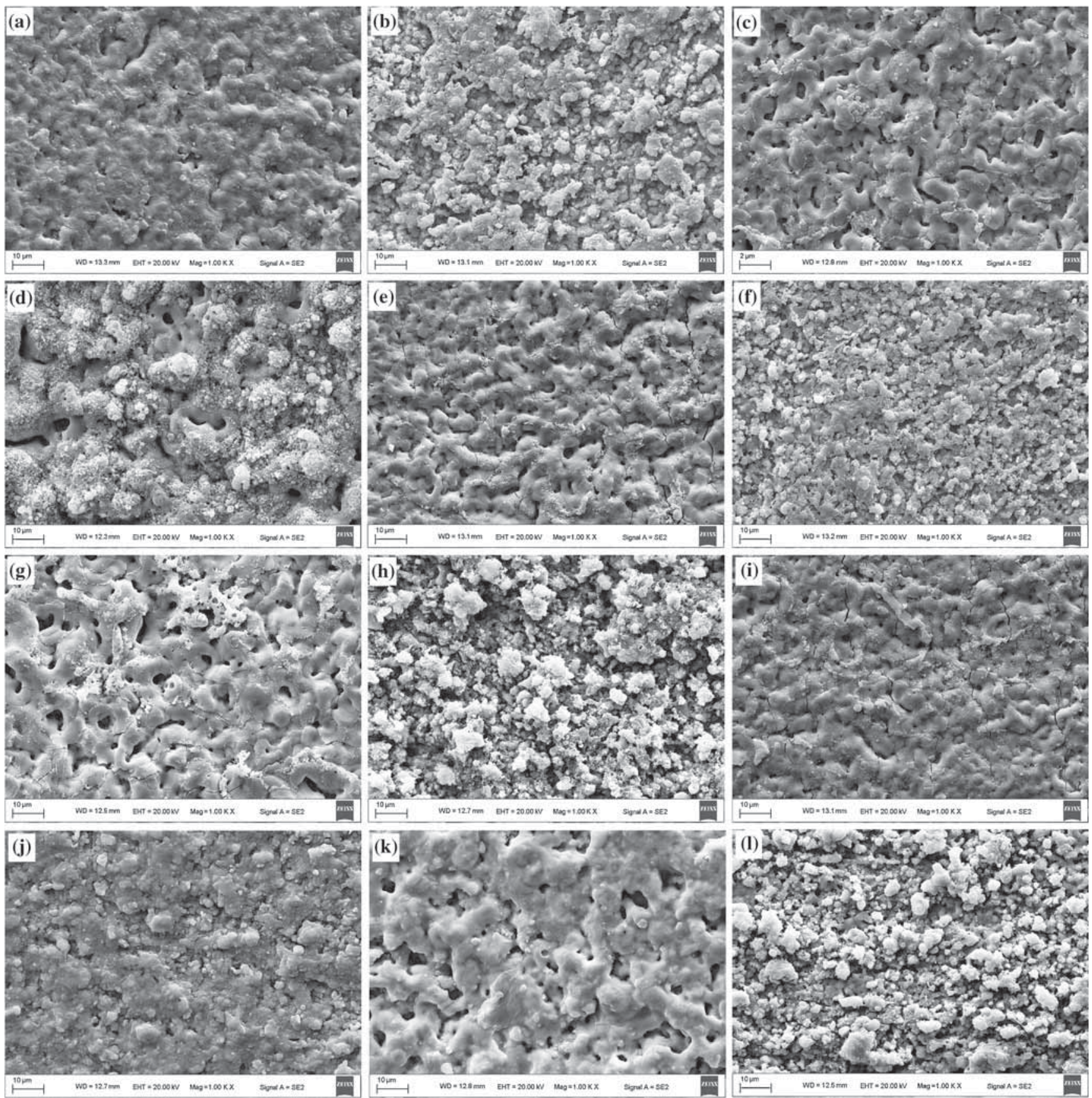

Figure 8. SEM image taken from samples surface: (a) sample SP-3-80; (b) sample SS-3-80; (c) sample SP-3-160; (d) sample SS-3160; (e) sample SP-9-80; (f) sample SS-9-80; (g) sample SP-9-160; (h) sample SS-9-160; (i) sample UP-80; (j) sample US-80; (k) sample UP-160; and (l) sample US-160.

results in the formation of thicker coatings through acceleration of both metallic substrate dissolution and oxide coating growth.

As thickness of the coatings formed in silicate-based electrolyte is typically greater than that of silicate-based electrolyte, ${ }^{20-23}$ here, SMAT process leads to the formation of some coatings in phosphate-based electrolyte which can compete with those formed in silicate-based electrolyte in terms of thickness. ${ }^{24,25}$ Considering that the coatings formed in phosphate-based electrolyte are typically less porous (shown in figure 8), the increase in their thickness induced by SMAT process can be favourable in the improvement of mechanical and corrosion properties of the coatings.

\subsection{Elemental distribution}

Table 5 shows elemental analysis of the samples using EDS analysis. As expected, phosphor exists only in coatings formed in phosphate-based electrolytes and is absent in silicate-based electrolytes. In phosphate electrolytes, 
Table 4. Weight and thickness of the coatings and area percentage of cavities existing at samples surface.

\begin{tabular}{|c|c|c|c|c|c|c|}
\hline $\begin{array}{l}\text { Code of } \\
\text { samples }\end{array}$ & $\begin{array}{l}\text { Weight before } \\
\text { the MAO } \\
(\mathrm{g})\left(m_{1}\right)\end{array}$ & $\begin{array}{l}\text { Weight } \\
\text { after the MAO } \\
(\mathrm{g})\left(m_{2}\right)\end{array}$ & $\begin{array}{c}\text { Weight } \\
\text { difference } \\
(\mathrm{mg})\left(m_{2}-m_{1}\right)\end{array}$ & $\begin{array}{c}\text { Weight } \\
\text { difference percent } \\
\left(m_{2}-m_{1} / m_{1} \times 100\right)\end{array}$ & $\begin{array}{c}\text { Coating } \\
\text { thickness }(\mu \mathrm{m})\end{array}$ & $\begin{array}{l}\text { Pores area } \\
\text { percentage } \\
\text { of surface }\end{array}$ \\
\hline SP-3-80 & 2.19140 & 2.20148 & 0.01008 & 0.45998 & 13.4 & 6.73 \\
\hline SS-3-80 & 2.23339 & 2.22866 & -0.00473 & -0.21179 & 11.6 & 9.17 \\
\hline SP-3-160 & 2.14610 & 2.13591 & -0.01019 & -0.47481 & 14.5 & 12.11 \\
\hline SS-3-160 & 2.18199 & 2.19904 & 0.01705 & 0.781397 & 20 & 8.43 \\
\hline SP-9-80 & 2.22461 & 2.22954 & 0.00493 & 0.221612 & 7.2 & 9.67 \\
\hline SS-9-80 & 2.15072 & 2.14943 & -0.00129 & -0.05998 & 12 & 11.54 \\
\hline SP-9-160 & 2.03364 & 2.03802 & 0.00438 & 0.215377 & 19.1 & 7.83 \\
\hline SS-9-160 & 2.17998 & 2.16855 & -0.01143 & -0.52432 & 13.1 & 12.92 \\
\hline UP-80 & 2.35044 & 2.35115 & 0.00071 & 0.030207 & 2.5 & 9.96 \\
\hline US-80 & 2.35201 & 2.33252 & -0.01949 & -0.82865 & 1.5 & 10.39 \\
\hline UP-160 & 2.31330 & 2.30251 & -0.01079 & -0.46643 & 4.9 & 10.49 \\
\hline US-160 & 2.25440 & 2.23828 & -0.01612 & -0.71505 & 4.9 & 13.58 \\
\hline
\end{tabular}

Table 5. Elemental analysis of the samples using EDS analysis.

\begin{tabular}{lccccc}
\hline $\begin{array}{l}\text { Code of } \\
\text { samples }\end{array}$ & Al & O & Si & N & P \\
\hline SP-3-80 & 70.5 & 26.3 & 0.8 & 1.9 & 0.5 \\
SS-3-80 & 74.7 & 18.9 & 4.5 & 1.9 & 0 \\
SP-3-160 & 69.5 & 27.2 & 0.7 & 2.2 & 0.4 \\
SS-3-160 & 59.2 & 30 & 9.2 & 1.6 & 0 \\
SP-9-80 & 73.1 & 24.7 & 0.8 & 0.9 & 0.5 \\
SS-9-80 & 80.1 & 16 & 2.2 & 1.7 & 0 \\
SP-9-160 & 69.8 & 27 & 1.2 & 1.9 & 0.1 \\
SS-9-160 & 69.5 & 20.7 & 7.4 & 2.4 & 0 \\
UP-80 & 71.8 & 24.8 & 1.5 & 1.3 & 0.6 \\
US-80 & 76.6 & 9.8 & 10.9 & 2.7 & 0 \\
UP-160 & 74.3 & 22.5 & 1.1 & 2 & 0.1 \\
US-160 & 72.2 & 21.7 & 4.6 & 1.5 & 0 \\
\hline
\end{tabular}

samples coated at current density of $80 \mathrm{~mA} \mathrm{~cm}{ }^{-2}$ have higher phosphor content as compared to those coated at $160 \mathrm{~mA} \mathrm{~cm}{ }^{-2}$. The silicon content of the samples coated in phosphate-based electrolyte is due to the presence of $\mathrm{Si}_{3} \mathrm{~N}_{4}$ nanoparticles absorbed in coating and also impurities in reacted metallic substrate, while for layers coated in silicate-based electrolyte this content is because of not only $\mathrm{Si}_{3} \mathrm{~N}_{4}$ nanoparticles and substrate, but also relates to the electrolyte; so, they have higher silicon content. It is worth to mention that for all samples nitrogen content came from $\mathrm{Si}_{3} \mathrm{~N}_{4}$ nanoparticles absorbed in the coating and might be used as a criterion for nanoparticles adsorption in the coating. In this regard, for samples coated at higher current densities, absorbed nanoparticle content was higher at surface. As samples of coating formed in phosphate-based and silicate-based electrolytes, map elemental analysis of samples SP-9-160 and SS-9-160 are shown in figure 9.

As shown in the figure, comparing two samples, silicon content in sample SS-9-160 is higher because of using silicate-based electrolyte while its distribution is mainly focused on bumps created in coating microstructure, which probably might be due to the presence of silicon oxide in these regions. Aluminium and oxygen distribution is uniform for both samples. Distribution of nitrogen as a criterion of nanoparticles presence in the coating indicates uniform distribution of nanoparticles in both samples; however, in the case of sample coated in silicate-based electrolyte nanoparticles concentrated mainly in central regions of the deposition induced by sparking and are very rare or absent in the valleys generated by pervious sparks. This implies nanoparticles absorption from spark centre and also absorbed nanoparticles discharge from around the oxide deposited from previous sparks by discharged melt oxide in new sparks. ${ }^{26}$ This effect is more obvious in silicate-based electrolyte, so higher amount of nanoparticles expand at surface of these coatings. For sample coated in phosphate-based electrolyte, also nanoparticle distribution is seen on the coating (but not inside the pores), implying similar absorption mechanism of the nanoparticles inside the coating. This mechanism has also been reported by other researchers. ${ }^{27-29}$

\subsection{Wettability angle}

Figure 10 demonstrates $h / d$ diagram with time. Also table 6 introduces the values obtained from wettability test for wettability angle and gradient values measured using the diagrams shown in figure 10. As shown in figure $10, \mathrm{~h} / \mathrm{d}$ values for samples coated in phosphate-based electrolyte is generally less than these values for samples coated in silicatebased electrolyte, implying that the drop fallen on surface of the coatings created in phosphate-based electrolyte has larger wettability angle. Coatings developed on phosphatebased electrolyte has phosphor-bearing components, which are intrinsically hydrophilic. ${ }^{30-33}$ So, it is normal that the wettability angle of these coatings is less than that of coatings created in silicate-based electrolyte.

Analysis of the results shown in table 6 implies a decreased wettability angle for samples coated in phosphate-based electrolyte as compared to those coated in silicate-based 


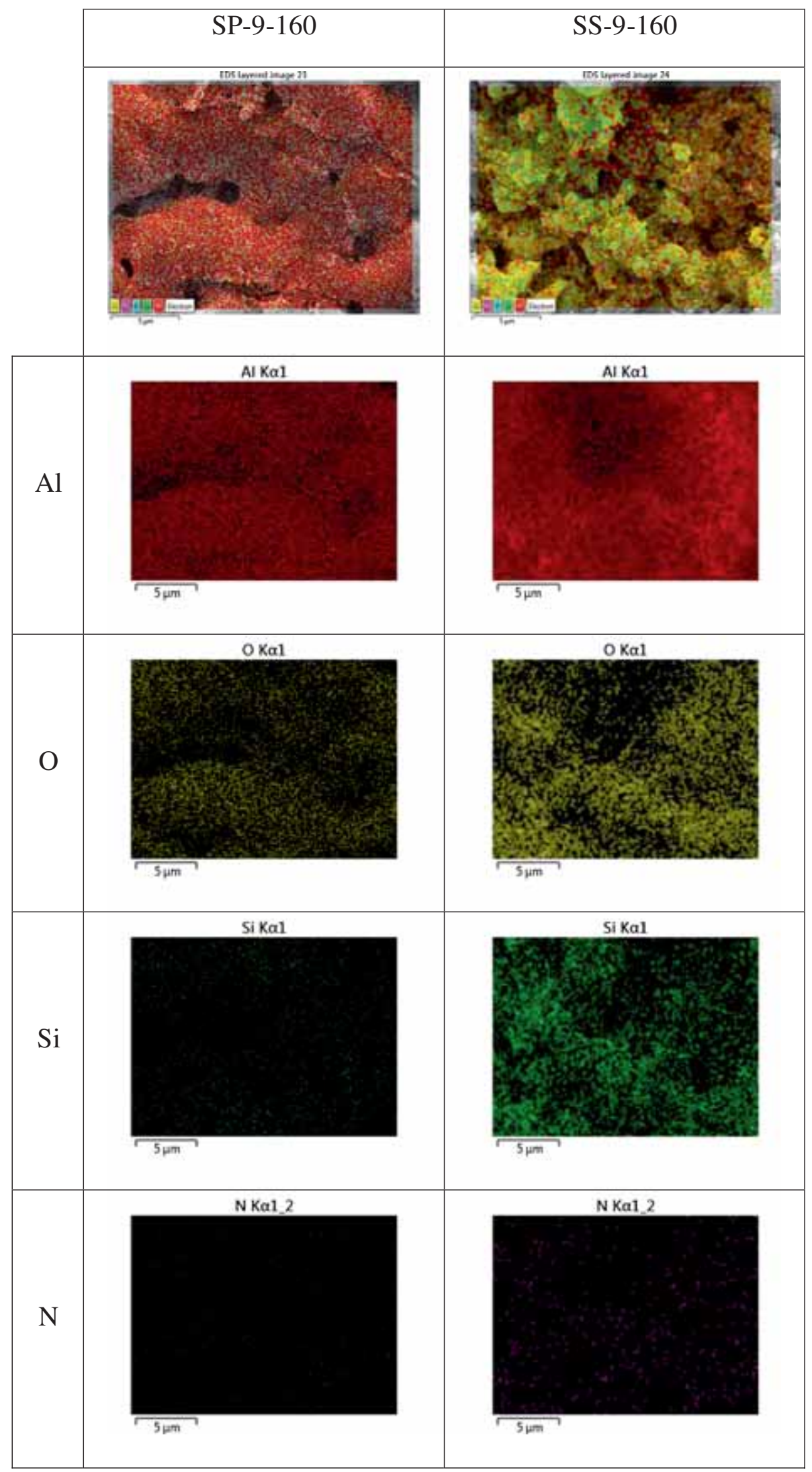

Figure 9. Element analysis map for samples SP-9-160 and SS-9-160. 
(a)
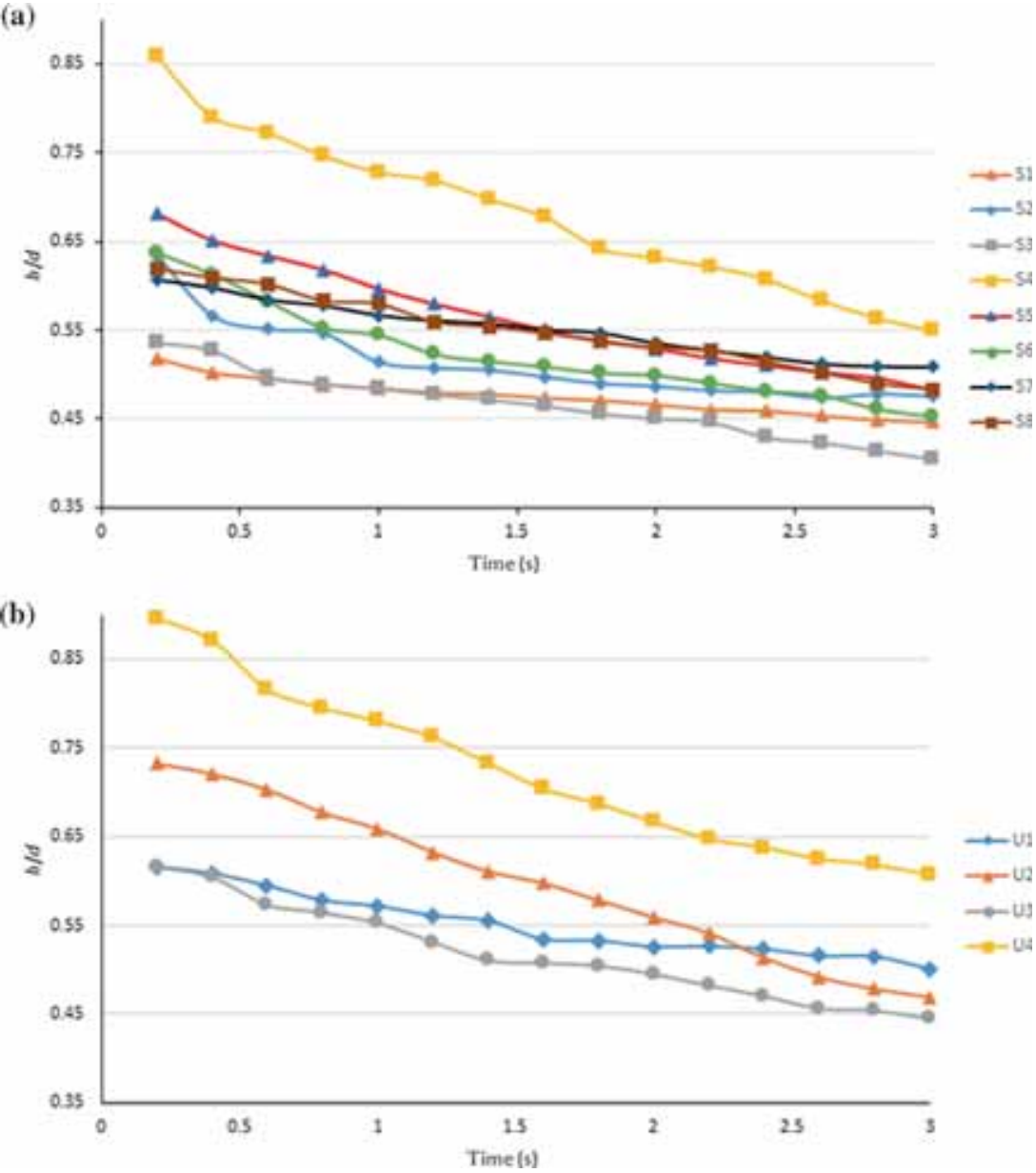

Figure 10. $h / d$ variation $v$ s. passing time diagram for: (a) SMATed samples and (b) unSMATed samples.

Table 6. Gradient of $h / d$ diagram and wettability angle of the samples.

\begin{tabular}{lcc}
\hline $\begin{array}{l}\text { Code of } \\
\text { samples }\end{array}$ & $\begin{array}{c}\text { Slope of } h / d \\
\text { diagram } \times 10^{-2}\end{array}$ & $\begin{array}{c}\text { Wetting } \\
\text { angle }\end{array}$ \\
\hline SP-3-80 & 2.5614 & 73.43 \\
SS-3-80 & 5.6513 & 76.61 \\
SP-3-160 & 4.6815 & 78.82 \\
SS-3-160 & 11.0144 & 82.80 \\
SP-9-80 & 7.094 & 79.38 \\
SS-9-80 & 6.5628 & 80.03 \\
SP-9-160 & 3.4993 & 81.87 \\
SS-9-160 & 4.8518 & 81.69 \\
UP-80 & 4.1231 & 82.59 \\
US-80 & 9.3881 & 77.60 \\
UP-160 & 6.1351 & 75.62 \\
US-160 & 10.3249 & 81.91 \\
\hline
\end{tabular}

electrolyte under the same conditions. Gradient of $h / d$ diagram with time indicates surface wettability rate. It depends on fine structure and coating's type and phases. For coatings developed in silicate-based electrolyte, gradient of $h / d$ curves is similar for samples with and without
SMAT. Considering the fine structure with high pores and dual-scale roughness of these coatings, this seems rather usual.

\section{Conclusions}

Results obtained from SEM examination of the samples reveal that samples coated in silicate-based electrolyte have a relatively rougher microstructure as compared to those coated in phosphate-based electrolyte. It seems that roughness of the samples coated in silicate-based electrolyte is dual-scale. For majority of the cases, area percentage of the pores existing at the surface of samples coated in silicatebased electrolyte is higher than that of phosphate-based electrolyte. Moreover, this value is higher for unSMATed samples as compared to those with SMAT.

The results for thickness values of the obtained coatings show that SMAT considerably enhances thickness of the coatings for both silicate-based and phosphate-based electrolytes. Examination of $h / d$ with time demonstrates that $h / d$ values for samples coated in phosphate-based electrolyte is mainly higher than that of samples coated in silicate-based 
electrolyte, implying that the droplet fallen on the surface of developed coatings has higher wettability in phosphate-based electrolytes. A comparison among the results obtained from wettability tests indicated a reduction in wettability angle for samples coated in phosphate-based electrolyte in contrast to the samples coated in silicate-based electrolyte under the same conditions.

\section{References}

1. Etefagh R, Shahtahmasebi N and Karimipour M 2013 Bull. Mater. Sci. 36411

2. Gupta G, Moon A P and Mondal K 2013 Bull. Mater. Sci. 36 51

3. Neelgund G M, Shivashankar S A, Chethana B K, Sahoo P P and Rao K J 2013 Bull. Mater. Sci. 341163

4. Saravanan M, Pillai R M, Pai B C, Brahmakumar M and Ravi K R 2006 Bull. Mater. Sci. 29679

5. Cao Y, Wang Y B, Chen Z B, Liao X Z, Kawasaki M, Ringer S P et al 2013 Mater. Sci. Eng. A 578110

6. Bonnot E, Helbert A L, Brisset F and Baudin T 2013 Mater. Sci. Eng. A 56160

7. Kaune V and Muller C 2013 Mater. Sci. Eng. A 5351

8. Chen A Y, Li D F, Zhang J B, Liu F, Liu X R and Lu J 2013 Mater. Sci. Eng. A $\mathbf{5 2 8} 8389$

9. Aliofkhazraei M, Rouhaghdam A S and Gupta P 2011 Crit. Rev. Solid State and Mater. Sci. 36174

10. Yerokhin A L, Snizhko L O, Gurevina N L, Leyland A, Pilkington A and Matthews A 2003 J. Phys. D: Appl. Phys. 36 2110

11. Kim C W, Choi J H, Kim H J, Lee D W, Hyun C Y and Nam S M 2013 Ceram. Int. 385621

12. Shen M J, Wang X J and Zhang M F 2013 Appl. Surf. Sci. 259 362

13. Shin K R, Ko Y G and Shin D H 2013 J. Alloys Comp. 536 S226
14. Athauda T J, Williams W, Roberts K P and Ozer R R 2013 J. Mater. Sci. 486115

15. Li Z, Zheng Y, Zhao J and Cui L 2013 J. Thermal Spray Technol. 21255

16. Psarski M, Celichowski G, Marczak J, Gumowski K and Sobieraj G B 2013 Surf. Coat. Tech. 22566

17. Hao G, Guo Y, Liu G and Zhang X M 2013 Adv. Mater. Res. 105-106 67

18. Wen L, Wang Y, Jin Y and Sun D 2013 J. Phys.: Conf. Ser. 419

19. Zhang J and Hao G 2013 Adv. Mater. Res. 146-147 1821

20. Malayoglu U, Tekin K C and Shrestha S 2013 Surf. Coat. Technol. 2051793

21. Sreekanth D, Rameshbabu N, Choudary K R and Rao K P 2013 Mater. Sci. Forum 710683

22. Tarakci M 2013 Mater. Charact. 621214

23. Wang L, Chen L and Fu W 2013 Adv. Mater. Res. 168-170 1203

24. Lv G, Gu W, Chen H, Feng W, Khosa M L, Li L et al 2006 Appl. Surf. Sci. 2532947

25. Wei-Chao G, Guo-Hua L, Huan C, Guang-Liang C, Wen-Ran F, Gu-Ling Z et al 2007 J. Mater. Process. Tech. 18228

26. Aliofkhazraei M and Rouhaghdam A S 2012 Electrochem. Commun. 2088

27. Matykina E, Arrabal R, Monfort F, Skeldon P and Thompson G E 2008 Appl. Surf. Sci. 2552830

28. Necula B S, Fratila-Apachitei L E, Berkani A, Apachitei I and Duszczyk J 2009 J. Mater. Sci.: Mater. Med. 20339

29. Necula B S, Apachitei I, Tichelaar F D, Fratila-Apachitei L E and Duszczyk J 2013 Acta Biomaterialia 72751

30. Bedi R S, Chow G, Wang J, Zanello L and Yan Y S $2013 A d v$. Eng. Mater. 14200

31. Kim C, Kendall M R, Miller M A, Long C L, Larson P R, Humphrey M B et al 2013 Mater. Sci. Eng. C 33327

32. Sheng Y, Tang X and Xue J 2013 J. Mater. Chem. 221290

33. Thian E S, Chang L, Lim P N, Gurucharan B, Sun J, Fuh J Y H et al 2013 Surf. Coat. Tech. 23129 